\title{
COMBINING A LATERALLY MOVED FLAP IN CLOSING LOCAL GINGIVAL RECESSION WITH THE USE OF STRAUMANN EMDOGAIN GEL
}

\author{
Georgiev T. \\ Department of Oral and Maxillofacial Surgery, \\ Faculty of Dental Medicine, Medical University - Varna, Bulgaria
}

\begin{abstract}
:
So far there is no universal solution regarding treatment of gingival recession. The author proposes his own version of updating one of the methods of treating gingival recession, namely a laterally moved flap with the addition of enamel matrix proteins. In the author's opinion, this method is the least invasive and there are the least contraindications to it.
\end{abstract}

Key words: gingival recession, laterally moved flap, Straumann Emdogain gel

Treatment of gingival recession of focal or generalized nature as an independent form of pathology or as a consequence of a complication of periodontitis is one of the most topical problems in periodontal surgery which still has not found its adequate solution.

The anatomical peculiarities of the oral cavity and the various forms of gingival recession necessitate an individual approach to the selection of techniques for their elimination.

In practice, in closing local defects of gingival recessions (GR), surgeons use the techniques of: laterally moved mucoperiosteal flap, coronary moved flap, as well as the two-stage method with the use of subepithelial connective tissue graft from the palate. The coronary moved flap is the most often used method of closing gingival recession, however, it has its contraindications related to the width of the attached mucosa. Obtaining a subepithelial connective tissue graft from the palate in the two-stage method before all necessitates two surgeries in the patient's mouth, furthermore contraindications to the method are the thinned mucosa of the alveolar process and a wide and shallow palate. Due to this reason, the author has decided to use the method of the laterally moved flap and added the already proven in practice Straumann Emdogain gel in order to improve the result of this method and reduce the percentage of recurrence related to it.

This method was first introduced by Grupe and Warren in 1956 and is convenient because there is only one surgical field, a richly vascularized flap and a possibility of complete covering of the root surface.

The conditions for implementation of the method concerned are: availability of a normal volume of attached mucosa, absence of deep gingival pockets, deep erosions of the teeth roots and normal depth of the vestibule of the oral cavity.

Until commencement of the surgical intervention for the purpose of eliminating GR, it is needed to be carried out a complete complex of hygienic measures.

In this article the author wants to share his experience in the surgical removal of local GR with the help of a laterally moved (partially split) pedicle flap and additionally used Straumann Emdogain gel.

6 patients underwent surgery following the method concerned - 4 of them with Miller class II, 2 of them - Miller class III.

The surgical method was described by Grigoriants L. A. and Badalian V. A. and involves the following: before commencement of the surgical manipulation, the softened cement in the region of the recession has to be removed and in this section has to be applied 3\% citric acid for 3-5 minutes.

After anesthesia is applied, a V-shaped incisions of the oral mucosa and the periosteum has to be made along the edge of the exposed root and the mucosal flap and are removed with the epithelium and the connective tissue. The angle of the incisions should be acute, thereby increasing the wound surface and facilitating the better healing of the flap.

The horizontal incision is made along the projection of the tooth-gingival end, receding at $3-5 \mathrm{~mm}$ from it in order to avoid GR in the area of the adjacent teeth.

The size of the flap has to be at least 1.5 times larger than the defect which is to be closed, and in order to ensure adequate vascularization, its base should not be less than the coronary part. The vertical incision in the donor part is made not to the bone, but has to reach to the intermediate fold and to be continued horizontally at an angle along width which is equal to the section of the GR. The split of the flap is made at the side of the distal incision using scalpel No 
15. In this way, half of the flap adjacent to the GR is laid back to the bone, i.e. the periosteum has to be moved with the flap, while the other part which is farther from the GR is removed without the periosteum, i.e. the periosteum guards the donor section of the bone against a potential risk of recession, and in addition to that, it facilitates the quicker healing of the process.

The mucoperiosteal flap is then detached and gently moved to the region of the GR, thereafter the periosteum is cut horizontally in its base along its whole width.

The author cleans the exposed root surface from plaque, tartar, roughnesses on the root surface after making the flap, he deepithelizes the vestibular side of the papilla between the teeth in order to make a connective-tissue bed for suturing the laterally moved flap. After that, he conditions the exposed root surface with Straumann PrefGel (EDTA) for $2 \mathrm{~min}$ or for $15 \mathrm{sec}$. with citric or phosphoric acid, washing thoroughly with physiological solution. After the final washing, it has to be avoided to contaminate the area with saliva or blood.

All patients were applied Straumann Emdogain gel in the wound. This gel is derivative of the enamel matrix and exhibits a better potential for root covering as compared to the laterally moved flap on its own, a good aesthetic result, formation of keratinized tissue and potential for regeneration of attachment.

Analyzing the data of the surgeries, it can be noted that in the 4 Miller class II patients there is $98 \%$ coverage of the defect, and in the 2 Miller class III $-90 \%$.

In conclusion, we have to note that cases of GR are often encountered in the clinical practice of an oral surgeon, however, little attention is paid to their treatment. The data provided by the author prove that when successful results are achieved in gingival plasty, all concomitant conditions have to be considered. Furthermore, it is important to strictly comply with the indications for surgical interventions.

\section{REFERENCES:}

1. Santana RB, Mattos CM, Dibart S. A clinical comparison of two flap designs for coronal advancement of the gingival margin: semilunar versus coronally advanced flap. J Clin Periodontol. 2010 Jun 1. PubMed PMID: 20528963.

2. Khuller N. Coverage of gingival recession using tunnel connective tissue graft technique. J Indian Soc Periodontol. 2009 May;13(2):101-5. PubMed PMID: 20407659; PubMed Central PMCID: PMC2847122.

3. Santamaria MP, Ambrosano GM, Casati MZ, Nociti FH Jr, Sallum AW, Sallum EA. The influence of local anatomy on the outcome of treatment of gingival recession associated with non-carious cervical lesions. J Periodontol. 2010 Jul;81(7):1027-34. PubMed PMID:
20214443

4. Chambrone LA, Chambrone L. Treatment of Miller Class I and II localized recession defects using laterally positioned flaps: a 24-month study. Am J Dent. 2009 Dec;22(6):339-44. PubMed PMID: 20178209.

5. Kassab MM, Badawi H, Dentino AR. Treatment of gingival recession. Dent Clin North Am. 2010 Jan;54(1):129-40. Review. PubMed PMID: 20103476.

6: Aroca S, Keglevich T, Nikolidakis D, Gera I, Nagy K, Azzi R, Etienne D. Treatment of class III multiple gingival recessions: a randomized-clinical trial. J Clin Periodontol. 2010 Jan;37(1):88-97. Epub 2009 Nov 30. PubMed PMID: 19968743.

7: Pourabbas R, Chitsazi MT, Kosarieh
E, Olyaee P. Coronally advanced flap in combination with acellular dermal matrix with or without enamel matrix derivatives for root coverage. Indian J Dent Res. 2009 Jul-Sep;20(3):320-5. PubMed PMID: 19884716

8: Moriyama T, Matsumoto S, Makiishi T. Root coverage technique with enamel matrix derivative. Bull Tokyo Dent Coll. 2009 May;50(2):97-104. PubMed PMID: 19815997.

9. Grupe HE, Warren RF. Repair of gingival defects by a sliding flap operation.J.Periodontol 1956;27:92-99.

10. Grigoriantz LA, Badalian The use of lateral removed flap for closing local recession of gingival, J. Clinical stomatology 1, 2002 p.54-56
Correspondence address:

Dr Tihomir Georgiev

18 Hristo Popovich St., Varna 9000, Bulgaria

e-mail: tgeorgeivphd@yahoo.com 